\title{
Effectiveness of video resources in nursing orientation before cardiac heart surgery
}

\author{
Ana Paula Amestoy de Oliveira ${ }^{1}$, Emillane Nogueira de Souza ${ }^{1}$, Lucia Campos Pellanda ${ }^{1}, 2 *$ \\ ${ }^{1}$ Universidade Federal de Ciências da Saúde de Porto Alegre (UFCSPA), Porto Alegre, RS, Brazil \\ 2Instituto de Cardiologia do Rio Grande do Sul / Fundação Universitária de Cardiologia (IC/FUC), Porto Alegre, RS, Brazil
}

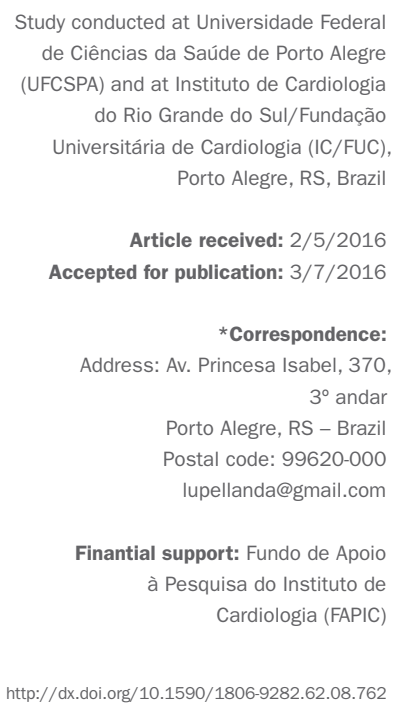

Study conducted at Universidade Federal de Ciências da Saúde de Porto Alegre (UFCSPA) and at Instituto de Cardiologia do Rio Grande do Sul/Fundação Universitária de Cardiologia (IC/FUC), Porto Alegre, RS, Brazil

Article received: 2/5/2016 Accepted for publication: $3 / 7 / 2016$

*Correspondence: Address: Av. Princesa Isabel, 370 , $3^{\circ}$ andar Porto Alegre, RS - Brazil Postal code: 99620-000 lupellanda@gmail.com

Finantial support: Fundo de Apoio à Pesquisa do Instituto de Cardiologia (FAPIC)

\section{SUMMARY}

Objective: To evaluate the effectiveness of video resources in increasing patient knowledge during preoperative orientation for cardiac surgery compared to standard orientation.

Method: Randomized clinical trial. Patients in the intervention group (IG) received bedside orientation with the aid of a short video and a slide presentation on the day prior to surgery. Patients in the control group (CG) received standard orientation. Allocation and analysis of knowledge were blinded. Analysis was performed according to the intention to treat principle.

Results: We included 90 patients, 45 in each group; $27.8 \%$ had incomplete primary education. There were no differences between groups in the baseline. After orientation, IG scored $7.20( \pm 1.56)$ and scored CG $2.71( \pm 1.96, \mathrm{p}<0,001)$. The topic "surgical room" had the lowest proportion of correct answers in CG (6.7\%), compared to IG (68.9\%). The question about "postoperative unit" was the one with the highest proportion of correct answers in IG (93.3\%), while in CG the proportion was $22.2 \%$. "Ventilatory support" had a low proportion of correct answers in IG (60\%), but still much higher than the correct answers in CG (17.8\%). Conclusion: Orientation performed with the aid of video resources is more effective for knowledge retention in preoperative patients, compared to verbal orientation alone.

Keywords: thoracic surgery, preoperative care, nurse orientation, audiovisual resources.

\section{INTRODUCTION}

Cardiac surgery has undergone major development in recent decades, and continues to rise. In this scenario, myocardial revascularization is still the most performed surgery, with a direct influence on the survival and quality of life of patients who depend on this invasive intervention. ${ }^{1}$

Cardiac surgeries are among the most complex invasive approaches. Additionally, for patients, there is still a great deal of ignorance about heart interventions, and anxiety prior to heart surgery can greatly undermine the understanding of key information. Thus, preoperative orientation appropriate to the emotional conditions, individuality, and characteristics of each patient is fundamental, ${ }^{2}$ reassuring patients and families, providing the patient with more knowledge about the procedure, answering questions and reducing anxiety. All of these elements can favor postoperative recovery. ${ }^{3}$

The traditional approach, with verbal guidance, can be greatly influenced by environmental conditions, patient anxiety and team workload, not to mention the patient's cognitive capacity. Moreover, it is extremely dependent on the professional who conveys the information. ${ }^{4}$ Therefore, orientation supported by alternative methods used throughout pre, inter, and postoperative care and which are still little explored, such as audiovisual aids, started being studied as of late. ${ }^{5}$

In view of the above, this study aims to verify the effectiveness of the use of audiovisual resources in the preoperative orientation of patients undergoing cardiac surgery to increase knowledge related to the procedure, compared to the usual orientation provided by the health team. 


\section{Method}

Randomized clinical trial (RCT), registered in the Brazilian Registry of Clinical Trials (ReBEC) and The Universal Trial Number (UTN) under the number U1111-1142-6554, conducted from May 2012 to August 2013 at Instituto de Cardiologia de Porto Alegre.

Study participants were patients undergoing myocardial revascularization (CABG) surgery. Patients aged 18 years or older, submitted to their first cardiac surgery and hospitalized for 72 hours or more prior to the surgical procedure were included in the study. Patients who underwent other associated surgeries, or who had neurological sequelae or any psychiatric disorders capable of altering their cognition, according to records in the chart, were excluded. We estimated that, in order to increase the level of knowledge from 50 to $80 \%$ in the intervention group, with alpha of 0.05 and $80 \%$ power, it would be necessary to include 45 patients in each of the groups.

Participants were allocated to an intervention group (IG) or a control group (CG) through the website www.randomizer.org. The opening of the envelope with the allocation of the group was made only after inclusion of the patient in the study, by an external researcher not involved with the present study, to ensure concealment of the allocation. Patient randomization used randomly permuted blocks.

The intervention of the study referred to patient orientation on CABG through audiovisual resources. Patient meetings were held at the bedside, the day before the surgery. Patient recruitment was performed from a list of surgeries available daily in the clinical-surgical hospitalization units, where patients scheduled to undergo CABG on the following day could be identified.

Patients in IG received orientation from the hospital staff, watched a video about the surgery, and a Power Point presentation of complementary information on CABG and patient recovery. First, each patient watched the video and then the slide show. Both presentations were performed on a laptop computer by one of the researchers, with duration of approximately 40 minutes. After the intervention, the patients' questions were answered.

The video was composed of animated images narrated in Portuguese, detailing the surgery (Nucleus Medical Media, catalog.nucleusinc.com/nucleusinde). The language used was easily understood by patients. The Power Point presentation included eight slides with the following titles/themes: Indication of coronary artery bypass surgery; other names; type of bypass; preoperative preparation; information about the operating room; recovery after surgery in the postoperative unit.
Patients who belonged to CG received usual guidance from the health team, according to the routine of the institution.

To evaluate the effectiveness of the use of audiovisual resources, we assessed patient knowledge as the main outcome, using a questionnaire built specifically for this study based on the specialized literature on CABG. ${ }^{1,6}$

The project was approved by the Ethics and Research Committees of the Universidade Federal de Ciências da Saúde de Porto Alegre (CEP-UFCSPA) and the Instituto de Cardiologia de Porto Alegre (CEP IC-FUC), CAAE: 10304212.6.0000.5333. All patients read and signed a Free and Informed Consent Form.

\section{Statistical analysis}

The data collected were analyzed using the Statistical Package for the Social Sciences (SPSS) statistical software, version 19.0. The analysis was performed according to the allocated group (intention-to-treat analysis). Categorical variables were analyzed as absolute (n) and percentage (\%) frequencies. Continuous variables were presented as means and standard deviation, or medians and interquartile ranges, according to their distribution. Student's t-test was used to evaluate the means between the groups at baseline and after the intervention. For proportions, chi-square test was used. A p-alpha value $<0.05$ was considered significant.

\section{Results}

Eighty-seven (87) patients were potentially eligible, of which seven did not meet inclusion criteria after initial screening. Therefore, 90 patients were randomized, 45 into the intervention group and 45 into the control group, as shown in Figure 1.

Mean age was $61.64( \pm 10.15)$ years in CG and 63.87 $( \pm 9.31)$ years in IG, most comprising male patients $(68.9 \%)$. As for education level, most participants did not complete primary education (27.8\%). Regarding the preoperative guidelines, 74 patients $(82.2 \%)$ received information within 24 hours before the procedure, while $16(17.8 \%)$ had not yet been informed about the procedure the night before. Among the patients who had already received orientation, 24 (32.4\%) had received such information from their doctors, 48 (64.9\%) from a nurse, and two (2.7\%) from a psychologist. Other professionals were not mentioned by the patients interviewed.

When questioned if the orientation received was enlightening, 57 patients (77.0\%) said yes, and $17(23 \%)$ said no. When asked how they felt about the procedure, 17 (18.9\%) said they were prepared and confident, 57 (63.3\%) said they were prepared but fearful, and $16(17.8 \%)$ said 


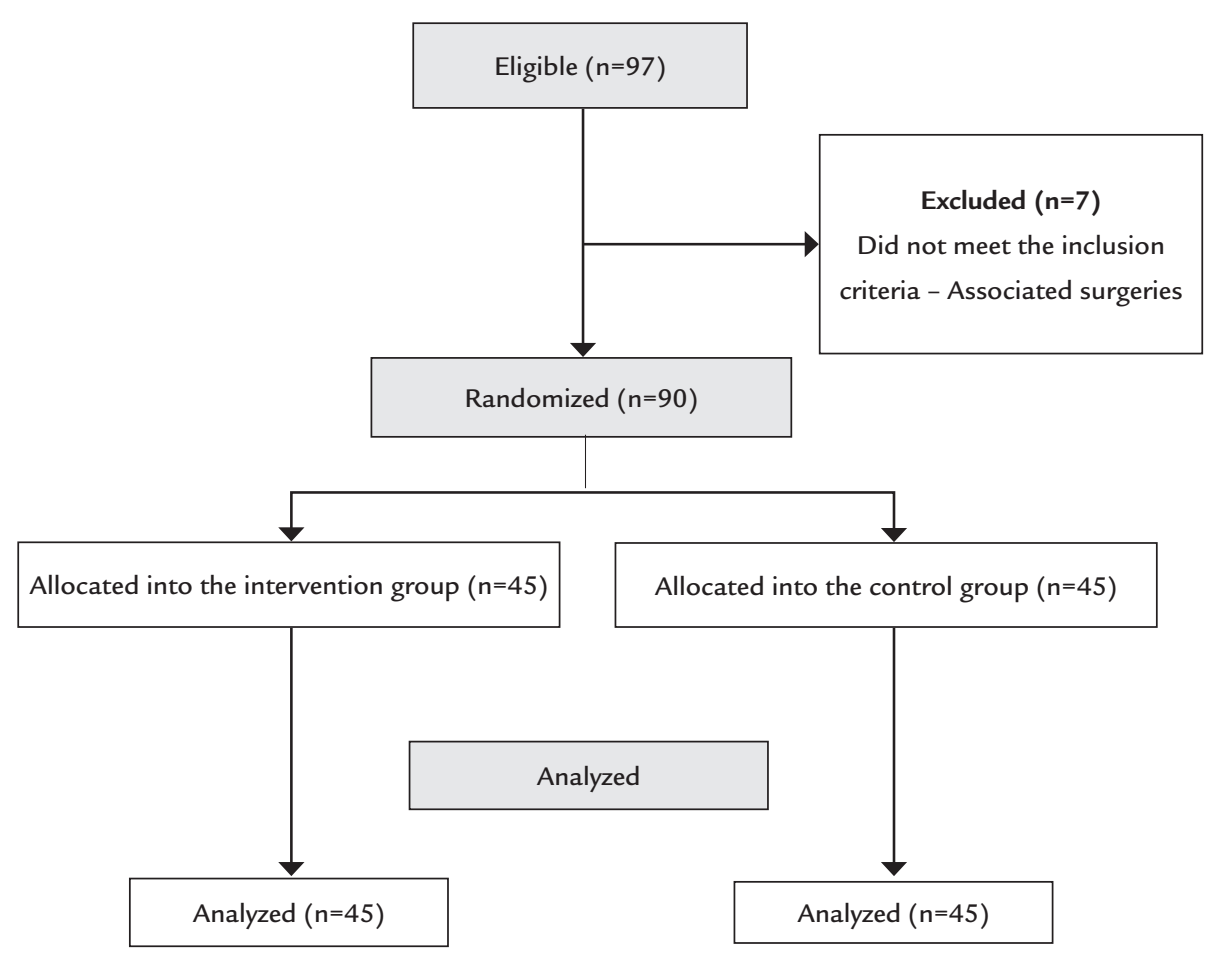

FIGURE 1 Study flowchart.

they were unprepared but confident. None of them declared themselves unprepared and fearful.

Regarding knowledge, the CG had an average of 2.71 $( \pm 1.96)$ correct answers, while the IG had an average of $7.20( \pm 1.56)$ correct answers $(p<0.001)$. Figure 2 shows the comparison of the medians of knowledge scores in the two groups.

Among the questions evaluated, the question related to "preoperative care" obtained a high percentage of correct answers in both groups (86.7\% of correct answers in IG and $64.4 \%$ in CG). The question about "surgical block" was the one with the lowest percentage of correct answers in CG, totaling $6.7 \%$. The question about the "postoperative unit" was the one that had the highest number of correct answers in IG, representing 93.3\%, while the CG had only $22.2 \%$ of correct answers. Another relevant question was related to "ventilatory support", with a low percentage of correct answers in both groups compared to other questions (60\% in IG and $17.8 \%$ in CG).

\section{Discussion}

This study verified the effectiveness of the use of audiovisual resources in the preoperative orientation of patients undergoing cardiac surgery to increase knowledge related to the procedure, the day before surgery. From the results obtained, it was possible to show that the use of audiovisual resources improved the patients' knowledge in relation to perioperative care in CABG compared to the control group, and, therefore, it is effective for orientations of patients in this context. All the orientation offered had the objective of presenting and/or improving information about perioperative care in CABG, in order to alleviate the lack of knowledge and fear related to the surgical procedure.

A study aimed at evaluating the efficacy and the acceptance of a video as a teaching strategy for oral hygiene among patients with hematologic diseases undergoing chemotherapy showed that the procedure was carried out more easily after watching the film $(\mathrm{p}<0.0001)$. The strategy was well accepted. ${ }^{7}$ Another study also used a video for guidance of patients undergoing cardiac catheterization diagnosis, whose results demonstrated the efficacy of this type of resource, similar to that observed in our study. ${ }^{8}$ Corroborating these findings, a randomized clinical trial aimed at determining whether educational videos were superior to routine verbal discussion to inform emergency patients about the risks and benefits of using intravenous contrast in computed tomography (CT) scans showed that the percentage of correct answers given by the IG was greater than that of the CG (68.1 vs. 47.8\%). In addition, IG 


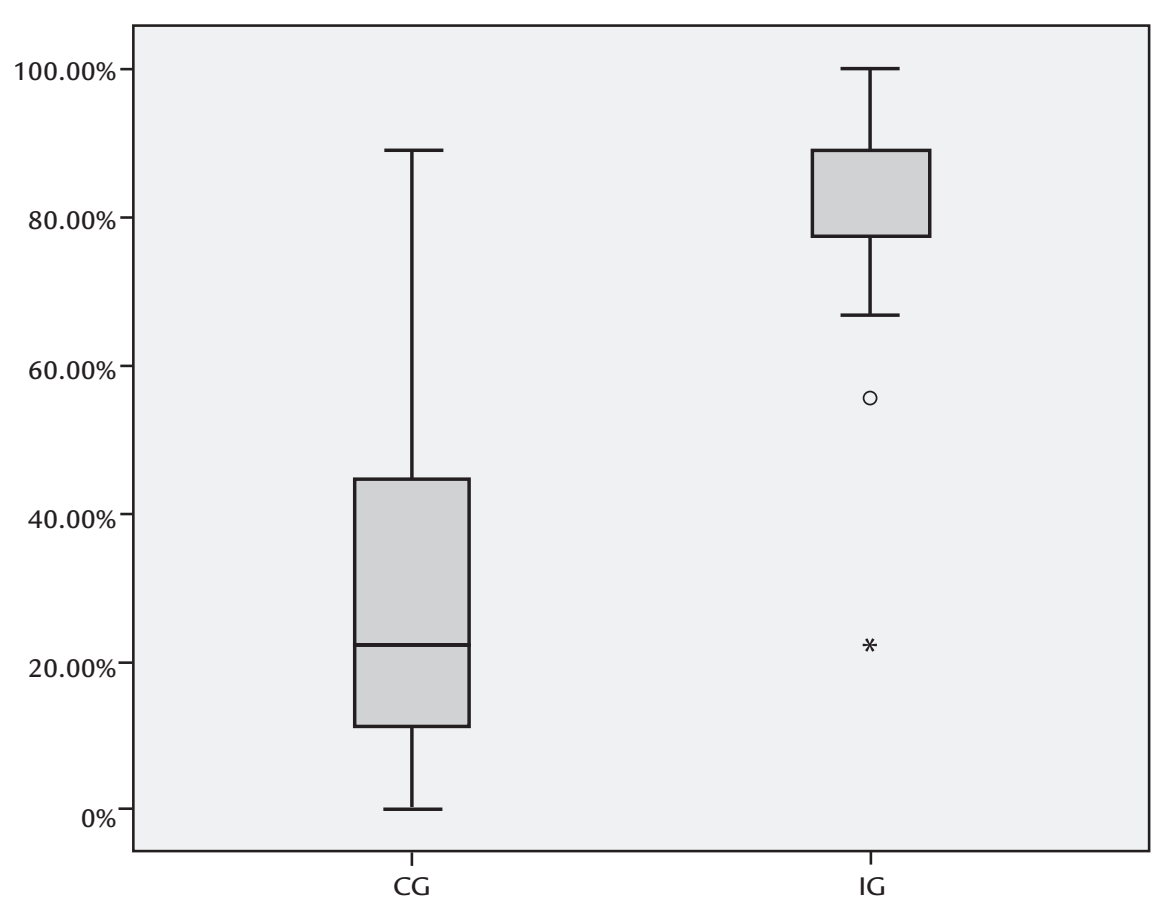

FIGURE 2 Diagram of boxes representing the medians, percentiles, and minimum and maximum values of correct answers between groups. CG: control group; IG: intervention group.

exhibited greater overall satisfaction with care, reflecting the importance of appropriate orientation for a positive patient experience with the procedure. ${ }^{9}$

It is important to mention that in a population with low levels of education, as in our study, the use of audiovisual resources favors the patient's understanding even more. A study evaluated the difference between the comprehension of individuals with formal education of less than or equal to 12 years (equivalent to complete secondary education in Brazil) and patients with higher education (over 12 years of education in Brazil), in relation to orientation provided through video and verbal orientations. In the subgroup with 12 years of education or less, the IG presented $73.1 \%$ of comprehension and the CG only $54.2 \%$ $(\mathrm{p}=0.0011)$. However, in the subgroup of patients with more years of study, IG patients had $82.3 \%$ and CG patients, $72.2 \%(\mathrm{p}=0.0002)$. This demonstrates that the potential benefit for patients with lower educational level may be even more pronounced with orientation using videos. ${ }^{10}$

As for knowledge questions, IG showed a better knowledge after the intervention regarding the indication of surgery (91.1\% of correct answers), while the CG was divided in relation to the answers, with $15.6 \%$ of the patients not knowing the reason why surgery was indicated or performed. When asked about the operating room, shortly before surgery, most CG patients (44.4\%) believed that they would be left alone and that they would be able to eat normally thereafter, while IG patients knew that they would be fed by tube after the intervention. These data indicate that traditional orientation is ineffective in clarifying even fundamental concepts, such as the indication or reason for surgery.

The profile of patients submitted to CABG in this study shows that the majority of the sample is composed of elderly male patients, data similar to other recently published studies. ${ }^{11}$ Knowledge about the profile of these patients enables the team to plan more accurately the care that will be offered to these patients. For elderly patients, for example, it is important to recognize the need for an individualized approach, due to limitations of visual acuity, memory, prevalence of depression, and other comorbidities. ${ }^{12}$

When asked about who provided them the initial orientation, most of the patients in this study in both groups cited the nurse, reinforcing the importance of the nursing professional in order to prevent and minimize the stressors related to a surgical procedure. ${ }^{13}$

Another important point is the perioperative patient flow (hospitalization - operating room - immediate postoperative unit - clinical and surgical hospitalization unit - hospital discharge). Some participants believed they would return to the room after the procedure and were unaware of the permanence in the immediate postoperative unit, where they remain after the procedure until they 
are referred to the hospitalization unit. The patient who does not know this flow does not recognize where he or she is, which can generate discomfort, anxiety, and stress. These feelings, added to the conditions naturally present in the postoperative period, may negatively influence the postoperative recovery from cardiac surgery.

The post-procedure visit is also an item that CG patients had difficulty responding because they did not know that immediately after surgery they would remain for 48 hours in an immediate postoperative unit. Many of them did not understand that their relatives could visit them there only during limited hospital hours, believing that their family members could come in at any time to see them or only when they were taken to the hospitalization unit.

Difficulty of contact at the bedside due to the presence of other patients/relatives in the same room was one of the study's limitation, since it interfered in the attention of the patients during the orientation. Patients were often unable to leave the bed so that the orientation could be provided elsewhere. In addition, the study sought to simulate the usual conditions of the unit, increasing the possibility of the information being generalized to other contexts.

The fact that the patient is not aware of aspects considered essential in the perioperative period is of concern, especially in a sector of the hospital where professionals should use orientation strategies that contemplate the different stages of the perioperative period. Most of the time, the team of the preoperative unit has a short-term relationship with the patient, who is received for the surgery and then, most of the time, is transferred to another unit. Thus, it is necessary to observe how the information is being offered, without turning it into a ritual, using methods that facilitate understanding, making the patient an active and subject, not a passive one. It is necessary to reserve time for the patient undergoing the surgical procedure, using it with quality, establishing, even in the short term, a relationship of care and confidence, and reassuring them in terms of the information provided.

This study allowed us to reflect on the importance of preoperative orientation. We observed that an effectively oriented patient has greater knowledge regarding the procedure that will be performed. This information serves as a basis for improving the type of care provided to patients who require cardiac surgery.

\section{Conclusion}

Orientation provided using audiovisual resources in the preoperative period of cardiac surgery is more effective for retention of knowledge compared to verbal orientation, especially regarding aspects related to the surgical procedure and the postoperative unit. Traditional orientation was not effective in clarifying important concepts such as the indication or reason for the surgery.

\section{ACKNOWLedgments}

The authors would like to thank the nursing team and the Research Unit of the Cardiology Institute/Fundação Universitária de Cardiologia.

\section{Resumo}

Recursos audiovisuais na orientação pré-operatória de cirurgia cardíaca

Objetivo: verificar a efetividade do uso de recursos audiovisuais para orientação pré-operatória de revascularização do miocárdio sobre o conhecimento a respeito do procedimento, quando comparado à orientação usual.

Método: ensaio clínico randomizado. Os pacientes do grupo intervenção (GI) receberam, na véspera da cirurgia, orientações audiovisuais à beira do leito, através de um vídeo explicativo e diapositivos, enquanto o grupo controle (GC) recebeu orientações de rotina da unidade. A randomização foi oculta e a análise do conhecimento foi cegada em relação ao grupo. A análise foi realizada por intenção de tratar.

Resultados: foram incluídos 90 pacientes, 45 em cada grupo; $27,8 \%$ dos pacientes incluídos apresentavam ensino fundamental incompleto. Não houve diferenças entre os grupos na linha de base. Após a orientação, o GI apresentou 7,20 $( \pm 1,56)$ acertos, enquanto o GC teve uma média de $2,71( \pm 1,96)$ acertos $(\mathrm{p}<0,001)$. O "bloco cirúrgico" foi o tópico que obteve o menor percentual de acertos no GC (6,7\%), quando comparado ao GI, com $68,9 \%$ de acertos. A questão sobre a "unidade de pós-operatório" foi a mais acertada pelo GI, representando $93,3 \%$ de acertos, enquanto o GC teve apenas $22,2 \%$ de acertos. O tópico "suporte ventilatório" apresentou baixo percentual de acertos em ambos os grupos, $60 \%$ no GI e $17,8 \%$ no GC.

Conclusão: orientações realizadas com recursos audiovisuais são mais efetivas para retenção do conhecimento quando comparadas a orientações verbais.

Palavras-chave: cirurgia torácica, cuidados pré-operatórios, orientação, mídia audiovisual. 


\section{References}

1. Lisboa LAF, Moreira LFP, Mejia OV, Dallan LAO, Pomerantzeff PMA, Costa $\mathrm{R}$, et al. Evolução da cirurgia cardiovascular no Instituto do Coração: análise de 71.305 operações. Arq Bras Cardiol. 2010; 94(2):174-81.

2. Assis CC, Lopes JL, Nogueira-Martins LA, Barros ALBL. Acolhimento e sintomas de ansiedade em pacientes no pré-operatório de cirurgia cardíaca. Rev Bras Enferm. 2014; 67(3):401-7.

3. Fonseca RMP, Peniche ACG. Enfermagem em centro cirúrgico: trinta anos após criação do Sistema de Assistência de Enfermagem Perioperatória. Acta Paul Enferm. 2009; 22(4):428-33.

4. Santos J, Henckmeier L, Benedet SA. O impacto da orientação pré-operatória na recuperação do paciente cirúrgico. Enferm Foco. 2011; 2(3):184-7.

5. Eubelen C, Brendel F, Belche JL, Freyens A, Vanbelle S, Giet D. Effect of an audiovisual message for tetanus booster vaccination broadcast in the waiting room. BMC Fam Pract. 2011; 12:104

6. Nicolau JC, Timerman A, Marin-Neto JA, Piegas LS, Barbosa CJDG, Franci A et al. Diretrizes da Sociedade Brasileira de Cardiologia sobre Angina Instável e Infarto Agudo do Miocárdio sem supradesnível do segmento ST (II Edição, 2007) - atualização 2013/2014. Arq Bras Cardiol. 2014; 102(3 Suppl. 1):1-78.
7. Carvalho EC, Stina APN, Marmol MT, Garbin LM, Braga FTMMB, Morelli $\mathrm{L}$, et al. Efeito de vídeo educativo no comportamento de higiene bucal de pacientes hematológicos. Rev Eletr Enferm. 2014; 16(2):304-11.

8. Torrano SK, Veiga VB, Goldmeier S, Azzolin K. Digital video disc explicativo em pacientes submetidos ao cateterismo cardíaco diagnóstico. Rev Latinoam Enferm. 2011; 19(4):1-7.

9. Cowan EA, Calderon Y, Gennis P, Mackiln R, Ortiz C, Wall SP. Spanish and English video-assisted informed consent for intravenous contrast administration in the emergency department: a randomized controlled trial. Ann Emerg Med. 2007; 49(2):221-30.

10. Souza AA, Souza ZC, Fenili RM. Orientacão pré-operatória ao cliente - uma medida preventiva aos estressores do processo cirúrgico. Rev Eletr Enferm. $2005 ; 7(2): 215-20$

11. Janssen AMS, Azevedo PR, Silva LDC, Dias RS. Perfil sociodemográfico e clínico de pacientes submetidos à cirurgia de revascularização do miocárdio Rev Pesq Saúde. 2015; 16(1):29-33.

12. Fernandes MVB, Aliti G, Souza EN. Perfil de pacientes submetidos à cirurgia de revascularização miocárdica: implicações para o cuidado de enfermagem. Rev Eletr Enf [internet]. 2009; 11(4):993-9.

13. Costa VASF, Silva SCF, Lima VCP. O pré-operatório e a ansiedade do paciente: a aliança entre o enfermeiro e o psicólogo. Rev SBPH. 2010; 13(2):282-98. 